\title{
Introduction to special section: Analog modeling as an aid to structural interpretation
}

\author{
Oriol Ferrer ${ }^{1}$, Tim P. Dooley ${ }^{2}$, Giacomo Corti ${ }^{3}$, Oskar Vidal-Royo ${ }^{4}$, Thomas E. Hearon IV ${ }^{5}$, \\ J. Reber ${ }^{6}$, and Fabien Graveleau ${ }^{7}$
}

Analog modeling provides the exploration and production industry with one of the most powerful and visual tools to understand the 4D structural evolution of sedimentary basins and individual or families of structures within those basins. Knowledge of the model setup and timing of syn-kinematic sedimentation combined with closely spaced serial sections of the completed models allows for the identification and understanding of structural processes within basins as well as providing possible geometries of poorly imaged structural geometries (e.g., subsalt and presalt structures, steep structures, thrust systems, structure, and stratigraphic geometries associated with diapir flanks) in seismic data. The recent application of new visualization techniques originally developed for other sciences (e.g., X-ray CTscanning techniques, particle image velocimetry, and 3D voxels), has fostered many improvements in the study, analysis, and applicability of physical models.

In this special section of Interpretation, we provide a general overview of the advanced techniques in analog modeling and their application to structural interpretation in hydrocarbon exploration. The eight articles included on this special section present a wide variety of analog models and analytical techniques that increase the visualization of their kinematic evolution. These new visualization methodologies also improve the comparison between analogs and nature (seismic or outcrop data), thus reducing the uncertainty during interpretation. Although the manuscripts are presented in the order in which they were available online, we grouped them by topic in the following summary. Two manuscripts deal the control of structural inheritance during extension. Three of them investigate the effect of base-salt relief on salt flow and suprasalt deformation in salt-bearing passive margins. Two focus on different aspects of fold-and-thrust belts, and the final article presents new results from a modified squeezebox design with innovative materials. We hope readers will find this selection of articles useful in their own work.

Through the use of X-ray CT-scanning techniques, Zwaan and Schreurs analyze the control of structural inheritance on the location and development of initial rift segments. The authors show that the degree of oblique extension has a major influence on how these rift segments interact and connect, while secondary inherited structures are of limited importance during these processes. D'Adda et al. describe and discuss the evolution of different sandbox models performed to test the influence of inherited transpressional structures at depth on the formation of shallower extensional fault systems. The authors compare experimental results with fault patterns interpreted on seismic lines from the Val d'Agri Basin (southern Italy).

Switching from rift systems to salt-bearing passive margins, Dooley et al. use a series of scaled physical models to investigate the effects of base-salt relief on salt flow and suprasalt deformation patterns. Their models demonstrate that the degree of deformation complexity increases as the base-salt relief increases its angle with respect to the dominant flow direction, resulting in zones of localized extension and contraction on the slope. Building upon these physical models, Dooley and Hudec interpret some puzzling shortening structures in the eastern Gulf of Mexico (folds and thrust stacks) that are present far from the toe-of-salt contractional province and are subparallel to the direction of early stage salt flow. Models consist of complex salt isopachs that produce convergent and divergent flow, which along with flow-velocity gradients, results in the rotation of early formed thrust belts and their translation far from the base-salt relief that caused their

\footnotetext{
${ }^{1}$ Universitat de Barcelona, Geomodels Research Institute, Departament de Dinàmica de la Terra i de l’Oceà, Barcelona, Spain. E-mail: joferrer@ ub.edu.

${ }^{2}$ The University of Texas at Austin, Bureau of Economic Geology, Austin, Texas, USA. E-mail: tim.dooley@bed.utexas.edu.

${ }^{3}$ Institute of Geosciences and Earth Resources, National Research Council, Firenze, Italy. E-mail: giacomo.corti@igg.cnr.it.

${ }^{4}$ Terractiva, Barcelona, Spain. E-mail: vidal.oskar@gmail.com.

${ }^{5}$ ConocoPhillips Subsurface and Technology, Houston, Texas, USA. E-mail: thomas.e.hearon@conocophillips.com.

${ }^{6}$ Iowa State University, Department of Geological and Atmospheric Sciences, Ames, Iowa, USA. E-mail: jreber@iastate.edu.

${ }^{7}$ Université des Sciences et Technologies de Lille 1, Laboratoire d'Océanologie et Géosciences, Villeneuve d'Ascq, France. E-mail: fabien. graveleau@univ-lille1.fr.

This paper appears in Interpretation, Vol. 5, No. 1 (February 2017); p. 1-2.

http://dx.doi.org/10.1190/INT-2016-1219-SPSEINTRO.1. @ 2017 Society of Exploration Geophysicists and American Association of Petroleum Geologists. All rights reserved.
} 
initial formation. In a similar way but focused on the Liguro-Provençal Basin (Western Mediterranean), Ferrer et al. describe the impact of pre-Messinian salt seamounts during the kinematic evolution of the margin and how the inherited relief alters salt flow and suprasalt deformation during gravitational gliding. The experiments demonstrate that seamounts locally interrupt the three-domain structural zonation of the margin, hinder downdip salt flow during early deformation, and constrain the development of local contraction and extension.

Moving on to fold-and-thrust belts, Carola et al. present a multidisciplinary approach integrating surface and subsurface data coupled with physical models to study the structural geometry and the kinematic evolution of a reactivated frontal structure in the southern Pyrenees (Ebro Foreland Basin). Shahpasand-Zadeh et al. use field observations and results of physical modeling to address the significance of a switch in convergence direction on tectonic evolution of the Alborz Mountains (northern Iran).

Finally, Mookerjee et al. present the first results from a new modeling apparatus designed to test deformation features at different strain rate conditions. The results of their experiments provide unique information about fault localization, the role of fluids, and fault asperity kinematics in a poly-phase system for modeling a variety of physical conditions within the earth's crust.
Although unfortunately not included in this special section due to time constrains, Roma et al. use a suite of scaled physical models to elucidate the interpretation of rift basins with syn-rift evaporites and multiple phases of extension that were subsequently inverted. The results of their experiments are compared with examples from the Lusitanian and Parentis basins. We encourage readers to check the next issue of Interpretation (May 2017) in which the manuscript will be published as a technical paper.

This special section would have been impossible without the disinterested effort and devotion of many people. First, we would like to acknowledge all the authors that shared their work and ideas with the community. Oriol Ferrer and Tim Dooley, as organizers and assistant editors of this section, would also like to thank the five geoscientists listed as coauthors of this introduction, who served as associate editors and guided the manuscripts throughout the review process, ensuring their quality. We also acknowledge the work by reviewers: M. Bonini, O. Duffy, V. Gaullier, H. Koyi, V. Mount, K. McClay, Z. Oner, M. Philippon, C. Schneider, J. Smit, R. Soto, B. C. Vendeville, P. Whitehouse, and the editors. Finally, we would like to thank to Kurt Marfurt, the Editor-in-Chief of Interpretation, as well as the editorial staff of the journal for their support, patience, and guidance in putting together this special section. 